\title{
Avaliação de software educativo na formação docente: articulando teoria e prática
}

\author{
Ana Cristina Barbosa da Silva ${ }^{1}$, Rozelma Soares de França ${ }^{2}$ \\ ${ }^{1}$ Centro Acadêmico do Agreste - Universidade Federal de Pernambuco (CAA - UFPE) \\ Caruaru - PE - Brasil \\ ${ }^{2}$ Centro de Informática - Universidade Federal de Pernambuco (CIn - UFPE) \\ Recife - PE - Brasil \\ kristtinna@bol.com.br, rsf2@cin.ufpe.br
}

\begin{abstract}
It is increasingly necessary to provide for the initial training of teachers, opportunities so they can use digital technology in teaching and learning. Taking this into consideration, this article presents the results of a university extension project that promoted the assessment of educational software by Chemistry, Physics, Mathematics and Pedagogy undergraduate students, considering the graphics, interface and specific pedagogical aspects of the above areas, based on criteria proposed in a checklist. The results show an understanding of the importance of evaluating educational software before using with students, nourishing a critical sense amongst the students who took this extension course.
\end{abstract}

Resumo. Cada vez mais é necessário proporcionar, durante a formação inicial dos professores, momentos para que possam utilizar a tecnologia digital nos processos de ensino e de aprendizagem. Deste modo, este artigo apresenta os resultados de um projeto de extensão que promoveu a avaliação de softwares educativos por graduandos de licenciaturas em Química, Física, Matemática e Pedagogia, considerando a interface gráfica, aspectos pedagógicos e específicos das áreas supracitadas, a partir de critérios propostos em checklist. Os resultados evidenciam a compreensão da importância de avaliar os softwares educativos antes do uso com os estudantes, cultivando um senso crítico nos participantes do curso.

\section{Introdução}

A tecnologia digital está cada vez mais presente nas atividades cotidianas e profissionais das pessoas, mas ainda é incipiente a sua presença na educação, na sala de aula propriamente dita, para a proposição de um processo de ensino e aprendizagem de modo sistemático e potencialmente útil (VALDIVIA, 2008; BASTOS, 2010). Esse fato é constatado tanto na educação básica como no ensino superior nas diversas instituições de ensino públicas e privadas do Brasil.

O que se percebe são as iniciativas governamentais possibilitando máquinas digitais aos professores e alunos, de acordo com Silva (2012), mas não há uma preparação eficiente e contínua para a utilização com o fim educacional direcionado às disciplinas. Essa preparação pode ser na formação inicial e na continuada dos profissionais da educação. Outras iniciativas são instituições de ensino da educação básica e superior que equipam seus laboratórios com 
máquinas com programas educativos e acesso à internet, mas com pouco uso ou com uso eficiente por alguns, porém não por todos os docentes.

Por isso, há uma grande necessidade de proporcionar, durante a formação inicial dos docentes, momentos para que possam utilizar a tecnologia digital nos processos de ensino e de aprendizagem, tanto utilizando tal tecnologia para a construção do próprio conhecimento na área em que vai se formar, como para utilizar essa tecnologia como material didáticopedagógico para uso no exercício futuro da profissão.

Nesta perspectiva, os graduandos podem ser levados a avaliar esse tipo de material e elaborá-lo, tendo em vista critérios que possam direcioná-los nesses dois processos. Foi o que propôs este trabalho que consistiu numa atividade de extensão, um curso, com o objetivo de levar os graduandos de licenciaturas à avaliação e à elaboração de software(s) educativo(s) (SE) de maneira criteriosa, observando as especificidades do ambiente digital, da prática pedagógica e do ensino da área de conhecimento da qual fazem parte. Neste artigo, serão expostos os resultados alcançados com as atividades de avaliação de softwares educativos realizadas na primeira parte do curso de extensão.

\section{Fundamentação teórica}

Tendo em vista a diversidade de materiais construídos para serem utilizadas no ambiente de ensino e aprendizagem, faz-se necessário uma avaliação criteriosa para a escolha daqueles que melhor auxiliem os professores em sua prática pedagógica e os alunos em sua aprendizagem. Assim, é cada vez mais necessário formar professores, seja na formação inicial ou continuada, para a escolha e uso de tecnologias digitais educacionais. Os SE se inserem nessas tecnologias, sendo definido como um dispositivo

planejado e elaborado para fins didáticos/pedagógicos, sendo, portanto, mediador de
conteúdos curriculares da esfera escolar e viabilizador dos processos de ensino e de
aprendizagem, necessitando da mediação de um profissional da área para o uso
eficiente do material. Acrescenta-se ainda que se trata de um instrumento imbuído de
linguagem e aportado no ambiente digital, o que o faz ser um instrumento com
especificidades peculiares em detrimento aos materiais do ambiente impresso
(SILVA, 2012, p. 29).

Atualmente há uma preocupação muito grande, pelos desenvolvedores, com a interface dos programas, desafio na área do design e da ergonomia, pois é necessário suprir as necessidades dos usuários e, por isso, desenvolvem-se novos produtos e sistemas, conforme afirmam Soares e Falcão (2013). De acordo estes autores, o 'termo 'design' vem sendo utilizado para descrever qualquer atividade criativa que atenda a promover uma ideia existente ou apresente uma alternativa original, que tenha sido estendida para vários campos de conhecimento" (SOARES e FALCÃO, 2013, p. 219). No entanto, o cuidado não deve ser apenas com a interface, mas também com os objetivos educacionais, pois, como afirmam Oliveira et al. (2010), deve-se avaliar a qualidade da interação, bem como a aprendizagem dos alunos, pois a "avaliação de um sistema é uma etapa importante do processo de desenvolvimento de software e avaliar a interface de sistemas educacionais é uma tarefa complexa, pois se deve considerar, dentre outros aspectos, o aprendizado de um conteúdo" (OLIVEIRA et al., 2010, p. 42). Para Gomes (2008) é importante considerar aspectos do processo de aprendizagem quando na elaboração de interfaces educativas, pois poucas teorias de interação humano-computador se preocupam com a abordagem da aprendizagem de conceitos específicos pelos usuários. 
Nesta perspectiva, para avaliar um SE, uma gama de conhecimento é necessária, envolvendo aspectos técnicos relativos à interface do programa, como também aqueles relacionados à forma como o conteúdo é apresentado ao aluno e especialmente à coerência das atividades com a literatura da área específica abordada no software, de modo a promover momentos de reflexão que levem à aprendizagem. Desta maneira, deve-se considerar que o software é desenvolvido tendo em vista objetivos pedagógicos, a partir de concepções de ensino e aprendizagem e envolve interlocutores situados no tempo e no espaço: os desenvolvedores e usuários no papel do docente e do discente.

No que concerne ao usuário, afirma-se que a interação do usuário com a máquina é ativa e responsiva, na perspectiva de Bakhtin (2003), pois, ao mesmo que tempo em que recebe as informações/enunciações da máquina, o usuário não é passivo porque essa relação requererá do interlocutor/usuário algumas ações cognitivas, bem como alguma atitude de resposta à máquina. Essas ações e atitudes tanto dizem respeito ao manuseio do aparelho como à interação com as enunciações que estão sendo processadas para o interlocutor/usuário e que, segundo Peres (2007, p. 45), ao abordar sobre os processos de interação social e mediação semiótica, essa mediação advém da interação entre indivíduos, mas "também do encontro de pessoas com máquinas, já que as interações que precederam um determinado produto são encapsuladas em mensagens, ícones e outros elementos na interface", sendo estes considerados, "nesse sentido, enunciados do desenvolvedor".

Os desenvolvedores terão os usuários como alvos, os quais estão inseridos em um ambiente específico de comunicação e de atividade social, em um processo de ensino e aprendizagem. Por isso, o SE carrega características da esfera de prática social educativa formal, sofrendo influência de subsídios didáticos que o antecede e que circula nessa mesma esfera. Portanto, o SE tem o objetivo de auxiliar na aquisição de habilidades propostas nos currículos das instituições de ensino.

Ao analisar a literatura sobre avaliação de software educativo, é possível constatar que tal processo é realizado por i) designers; ii) professores, especialistas de um domínio específico, e iii) alunos, usuários das tecnologias. Neste trabalho, o foco está sobre as atividades que contam com a presença do professor no processo de avaliação. No que diz respeito ao tipo de avaliação de software, há a formativa e a somativa (PREECE et al., 2005). A primeira é realizada quando o software está em desenvolvimento e objetiva verificar se o produto continua a atender às necessidades dos usuários, enquanto que a segunda é realizada para verificar o sucesso do produto finalizado. A somativa foi o tipo de avaliação de software contemplada neste trabalho.

\section{Método}

O curso, "Avaliando e elaborando softwares educativos: Química, Matemática, Física e Pedagogia", teve a duração de $36 \mathrm{~h}$, divididas em três módulos com quatro encontros de $8 \mathrm{~h}$ e um seminário de $4 \mathrm{~h}$ de palestras e apresentação dos softwares, sendo realizados no Centro Acadêmico do Agreste, da Universidade Federal de Pernambuco, na cidade de Caruaru, Pernambuco. O módulo de avaliação de softwares teve a carga horária de $8 \mathrm{~h}$. Os participantes do curso foram 28 graduandos de diversos períodos dos cursos de Licenciaturas em Química, Física, Matemática e Pedagogia.

O desenvolvimento do encontro de avaliação de SE correspondeu basicamente à explicação pelos proponentes do curso do que vêm apontando as pesquisas sobre a tecnologia digital na educação; definição de SE; apresentação e discussão sobre a tabela de critérios 
técnicos e pedagógicos para avaliação de SE propostos em checklist elaborada por Silva (2012) (Figura1); elaboração dos critérios específicos de cada área pelos próprios graduandos; conhecimento e exploração dos softwares disponibilizados no curso das áreas de ensino de Química, Física, Matemática e Língua Portuguesa para Pedagogia.

O propósito de se usar checklist para a avaliação foi o fato de tê-lo utilizado em outras avaliações com outros SE e se obter um bom resultado. No entanto, esse instrumento é apenas uma de tantas outras maneiras de se avaliar SE. O checklist propicia ter uma base, antes de utilizar o SE, do que se deve contemplar no material, mesmo sem um teste de uso com professores e estudantes, permitindo uma avaliação preditiva e direcionando o avaliador a alguns aspectos considerados importantes para compor tais softwares. No entanto, sabe-se que além do checklist, é preciso avaliar o SE a partir de sua utilização na sala de aula para identificar o impacto na aprendizagem com uso da interface educativa (GOMES, 2008).

Os estudantes avaliaram apenas o software de sua área e este processo foi constituído das seguintes etapas: avaliação do manual de utilização do software; avaliação do software, preenchendo a tabela de critérios e realizando os cálculos para verificação da nota obtida em cada dimensão da avaliação: técnica, pedagógica e específica; elaboração de um relatório dos resultados; socialização e discussão das avaliações dos softwares. Correspondeu a um total de 14 avaliações, uma vez que os participantes trabalharam em dupla. Ao final, houve ainda a avaliação do curso pelos participantes.

No que concerne às três dimensões de avaliação de um SE consideradas, na dimensão técnica, houve o enfoque na interface e na interatividade, pois o ambiente digital requer conhecimentos e habilidades que antes não eram exigidos ao lidar com outros tipos de tecnologias. Requer saber lidar com o manuseio da máquina e as especificidades dos enunciados manifestos em textos verbais e não verbais, com os ícones e as maneiras desses enunciados aparecerem na tela, tais como as manifestações hipertextuais e hipermodais.

O hipertexto eletrônico pode ter um nível maior ou menor de multissemiose, ou seja, de hipermodalidade, contemplando imagens, animações, sons, gráficos e links. Para a realização das avaliações dos SE, a parte verbal, não verbal e a parte de sons e movimentos do hipertexto foram separadas com o intuito de facilitar e viabilizar a identificação de tais itens nos materiais e com isso verificar a possibilidade pedagógica do instrumento didático-pedagógico. Desta forma, as categorias consideradas na parte técnica, juntamente com seus critérios, foram: Documentação, compatibilidade e instalação; Navegabilidade e feedback; Refacção de atividade e interpretação de erro; Elementos da interface.

$\mathrm{Na}$ dimensão pedagógica, considerou-se que no trabalho com os softwares com viés no ensino, é necessário haver intermediação de um profissional agente de aprendizagem que possa direcionar a construção do conhecimento, pois, como afirmam Oliveira et al. (2010), no caso do SE, se ele tem a característica de ser autônomo seu fundamento é o ensino programático, cujas informações são padronizadas e por si só promovem o ensino de qualquer conteúdo independentemente das situações de uso.

É importante mencionar que os SE, ou outros recursos tecnológicos, devem ser elaborados contemplando projetos pedagógicos e com a participação dos profissionais das áreas de ensino, ao mesmo tempo em que esses artefatos devem deixar claro aos usuários quais são os objetivos pedagógicos no seu uso, como os usuários vão utilizar tais ferramentas, quais atividades estão sendo propostas, entre outros aspectos para o fazer pedagógico. 
Pensando numa melhor prática pedagógica com a utilização da informática, enfatiza-se a aprendizagem focada no aprendiz, considerando que no processo de ensino o professor tem o papel de mediador e que as escolhas de recursos educacionais têm o papel de direcionar e facilitar a aprendizagem, o que requer o envolvimento do aluno nas ações de aprender. Portanto, as categorias com seus respectivos critérios foram: Fundamentos e objetivos pedagógicos; Conteúdo pedagógico; Recursos motivacionais e responsivos.

$\mathrm{Na}$ dimensão específica há a necessidade de se considerar o que as teorias da área disciplinar propõem como sendo objeto de ensino e aprendizagem, partindo da melhor maneira de se trabalhar os conteúdos para o desenvolvimento de habilidades nos estudantes relacionadas à área. Nesta perspectiva, seria o que propõem as teorias de Ensino de Química, de Física, de Matemática e de Língua Portuguesa em Pedagogia para o que deve ser objeto de ensino e como deve se dar a abordagem dos conteúdos que aparecerem nos softwares de cada área. Esta dimensão do $\mathrm{SE}$, que corresponde aos critérios, foi elaborada pelos próprios graduandos das licenciaturas sob a orientação dos executores do curso.

A equipe executora do curso procedeu a avaliação do curso e de seus resultados através de observação e anotação, do preenchimento da tabela de critérios e da análise dos relatórios de resultados dos participantes.

\section{Resultados e discussões}

\subsection{Avaliação dos softwares educativos pela equipe executora do curso}

Antes de ir a campo, a equipe executora do curso realizou a avaliação dos softwares educativos a partir do quadro de critérios de avaliação propostos por Silva (2012). Como pode ser observado na Figura 1, o quadro é estruturado em categorias, compreendidas em técnica, pedagógica e específica, e cada uma delas possui critérios próprios que devem ser considerados na avaliação de SE. Além disso, há uma escala de valores para que o avaliador assinale uma opção de percentual relativa a cada critério: i) 0: quando não houver nenhuma ocorrência do critério no software; ii) 1: quando se verificar a ocorrência entre $1 \%$ e $35 \%$; iii) 2: quando se observar que o critério ocorreu entre $36 \%$ e $70 \%$; iv) 3: quando se perceber que a ocorrência do critério foi entre $71 \%$ e $100 \%$; v) NAp (não se aplica): quando o critério não se aplicar ao software em análise.

O quadro dispõe também de um espaço para comentários permitindo uma avaliação qualitativa do material, complementando informações da parte quantitativa.

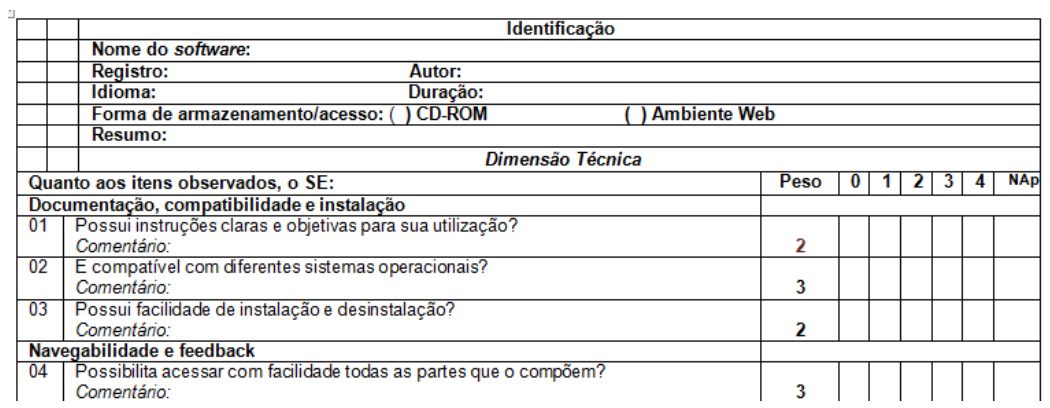

Figura 1. Recorte da tabela de critérios de avaliação de SE proposta por Silva (2012)

Os softwares educativos, como objetos de aprendizagem, escolhidos para serem utilizados no curso foram: Desafio Eletrizante (Física); Construtora RIVED (Matemática); Por uma Vírgula (Português) e Dentro das Leis (Química), todos desenvolvidos pelo Grupo de 
Pesquisa e Produção de Ambientes Interativos e Objetos de Aprendizagem (PROATIVA) e disponíveis em <http://www.proativa.vdl.ufc.br/oa.php>. A Figura 2 apresenta o resultado quantitativo das análises, nas dimensões Técnica e Pedagógica.

\begin{tabular}{|c|c|c|c|c|}
\hline \multicolumn{5}{|c|}{ Desafio Eletrizante (Física) } \\
\hline Conceitos & Fraco & Regular & Bom & Ótimo \\
\cline { 3 - 5 } & \multirow{2}{*}{$1 \%-25 \%$} & $26 \%-50 \%$ & $51 \%-75 \%$ & $76 \%-100 \%$ \\
\hline Dimensões & & & & $X$ \\
\hline Técnica & & & $X$ & \\
\hline Pedagógica & & & & \\
\hline
\end{tabular}

\begin{tabular}{|c|c|c|c|c|}
\hline \multicolumn{5}{|c|}{ Construtora RIVED (Matemática) } \\
\hline Conceitos & Fraco & Regular & Bom & Ótimo \\
\cline { 3 - 5 } & \multirow{2}{*}{$1 \%-25 \%$} & $26 \%-50 \%$ & $51 \%-75 \%$ & $76 \%-100 \%$ \\
\hline Dimensões & & & $X$ & \\
\hline Técnica & & & $X$ & \\
\hline Pedagógica & & & & \\
\hline
\end{tabular}

\begin{tabular}{|c|c|c|c|c|}
\hline \multicolumn{5}{|c|}{ Por uma vírgula (Português) } \\
\hline Conceitos & Fraco & Regular & Bom & Ótimo \\
\cline { 3 - 5 } & \multirow{2}{*}{$1 \%-25 \%$} & $26 \%-50 \%$ & $51 \%-75 \%$ & $76 \%-100 \%$ \\
\hline Dimensões & & & & $X$ \\
\hline Técnica & & & $X$ & \\
\hline Pedagógica & & & \multicolumn{2}{|}{} \\
\hline
\end{tabular}

\begin{tabular}{|c|c|c|c|c|}
\hline \multicolumn{5}{|c|}{ Dentro das Leis (Química) } \\
\hline \multirow{2}{*}{ Conceitos } & Fraco & Regular & Bom & Ótimo \\
\cline { 3 - 5 } & \multirow{2}{*}{$1 \%-25 \%$} & $26 \%-50 \%$ & $51 \%-75 \%$ & $76 \%-100 \%$ \\
\hline Dimensões & & & $X$ & \\
\hline Técnica & & & $X$ & \\
\hline Pedagógica & & & \multicolumn{3}{|c}{} \\
\hline
\end{tabular}

Figura 2. Conceitos das dimensões Técnica e Pedagógica dos SE

No software Desafio Eletrizante, a categoria técnica obteve conceito Ótimo, pois foi constatado que há, em nível 4, instruções claras e objetivas para uso do SE; compatibilidade com diferentes sistemas operacionais; fornecimento de feedback às entradas de dados do usuário; interrupção e retomada a uma tarefa a qualquer instante; anulação da última ação realizada; fornecimento de explicações para correção do erro do estudante, quando houver; presença de links, ícones, botões, imagens e animações pertinentes ao contexto, favorecedores do processo de aprendizagem. O SE não fornece a solução após longa persistência do erro, todavia, os demais critérios desta categoria foram classificados no nível 3. Desse modo, considera-se que o software apresenta uma potencialidade que possa permitir uma interação e um trabalho pedagógico de qualidade.

No tocante à dimensão pedagógica, esta obteve conceito Bom, pois há guia de apoio ao trabalho docente com o SE; identificação dos objetivos pedagógicos; o conteúdo é adequado ao público-alvo, atualizado em relação às teorias da área e sua abordagem é coerente à proposta pedagógica a que se propôs; há ênfase a uma disciplina específica, neste caso, Física; há feedbacks favorecedores da aprendizagem, por ajudarem na interpretação do aluno sobre seus erros e acertos. Todavia, registraram-se também ocorrências no nível 0 correspondentes à explicitação da fundamentação pedagógica que embasa o SE; à abordagem interdisciplinar, bem como do registro de desempenho do estudante e ao favorecimento do trabalho em equipe, situação esta que poderá ser revertida de acordo com o direcionamento dado pelo professor. Os demais aspectos foram assinalados no nível 3. Como a maioria dos critérios foi contemplada a contento, o Desafio Eletrizante pode propiciar um bom trabalho pedagógico, podendo ajudar os processos de ensino e de aprendizagem.

No software Construtora RIVED a categoria técnica obteve conceito Bom, já que a maioria dos critérios foi registrada nos níveis 3 e 4 referentes à compatibilidade do SE com diferentes sistemas operacionais; facilidade de acesso a todas as partes que compõem o aplicativo; fornecimento de feedback às entradas de dados do estudante; possibilidade de interromper e retornar a uma tarefa a qualquer instante; anulação da última ação realizada; 
orientação e possibilidade de realizar exercícios, na ocorrência de erros; fornecimento de explicações que ajudem o estudante a corrigir os erros; presença de links, ícones, botões, textos, hipertextos, imagens e animações pertinentes ao contexto e favorecedores da aprendizagem. Por outro lado, outros critérios foram assinalados nos níveis 0 e 1 referente à presença de instruções claras e objetivas para uso do SE; fornecimento da solução após longa persistência do erro e presença de recursos de som e efeito sonoro em quantidade e qualidade adequadas à facilitação da aprendizagem do estudante. Neste SE, considera-se que a categoria técnica se apresenta em boas condições de proporcionar ao usuário facilidade no seu uso.

Em relação à dimensão pedagógica, o SE Construtora RIVED também obteve conceito Bom, uma vez que há guia de apoio pedagógico ao professor; identificação dos objetivos presentes no SE; os conteúdos e abordagens são adequados ao público-alvo, atualizados em relação às teorias da área e coerentes à proposta pedagógica a que se propôs; há diferentes níveis de complexidade nas atividades; há recursos motivacionais para despertar e manter a atenção do estudante ao longo da interação; há emissão de feedback encorajador e isento de carga negativa mediante resposta inadequadas; favorece a interpretação do estudante sobre seus erros e acertos e o ajuda a ver suas respostas sob diferentes ângulos, levando o estudante à reflexão. Porém, os fundamentos pedagógicos do SE não são explicitados; ele foca em apenas uma disciplina, não havendo uma abordagem interdisciplinar; o desempenho do estudante nas atividades não é registrado e não há favorecimento explícito do trabalho em equipe com o uso do programa. Nesta categoria, considera-se que o SE oferece bons subsídios para que a prática pedagógica possa ser viabilizada a contento.

O software Por uma vírgula obteve conceito Ótimo na dimensão técnica, uma vez que a maioria dos critérios obteve níveis 3 e 4 referente a instruções de uso; compatibilidade com diferentes sistemas operacionais; navegabilidade e feedback às entradas de dados do estudante; possibilidade de refacção das atividades e auxílio ao estudante no fornecimento de explicações para correção de erros durante uma tarefa; presença de elementos como links, ícones, botões, textos, hipertextos, imagens e animações favorecedores do interesse dos estudantes e pertinentes ao contexto. Poucas ocorrências foram encontradas no nível 0 correspondentes ao fornecimento da solução após longa persistência do erro e presença de som e efeito sonoro favorecedores da aprendizagem dos estudantes. Desse modo, verifica-se que esta dimensão foi projetada adequadamente e pode apoiar satisfatoriamente as atividades na disciplina.

No que se refere à dimensão Pedagógica, esta obteve conceito Bom, já que quatro critérios apareceram em nível 0 no SE: explicitação dos fundamentos pedagógicos que embasam o Por uma vírgula; abordagem interdisciplinar; registro de desempenho do estudante e favorecimento ao trabalho colaborativo. Além disso, observou-se que nas atividades há poucas variações no grau de complexidade e em apenas alguns dos feedbacks há fornecimento de informações que ajudem o estudante a refletir sobre seus erros e acertos. Por outro lado, os critérios referentes ao fornecimento de guia de apoio ao trabalho do professor; identificação de objetivos pedagógicos do SE; conteúdo adequado ao público-alvo, atualizado em relação às teorias da área e coerente à proposta pedagógica a que se propôs; ênfase em uma disciplina específica; presença de recursos motivacionais e emissão de feedback encorajador e isento de carga negativa mediante respostas inadequadas foram contemplados a contento, podendo possibilitar um trabalho pedagógico de qualidade.

O software Dentro das Leis obteve conceito Bom em sua dimensão técnica, uma vez que a maioria dos critérios foi contemplada nos níveis 3 e 4 e poucas ocorrências foram constatadas nos níveis 0 e 2 . Nesse sentido, destaca-se a presença de documentação ao 
professor e compatibilidade do SE com diferentes sistemas operacionais; facilidade no acesso às partes do programa; fornecimento de feedback imediato às entradas de dados do estudante; possibilidade de interromper, retornar e reiniciar uma tarefa a qualquer instante; possibilidade de anulação à última ação realizada; orientação ao estudante, na ocorrência de erros na resolução dos exercícios propostos; presença de elementos de interfaces favorecedores do interesse e da aprendizagem, como links, ícones, botões, imagens e animações. Ainda, o SE permite que o usuário persista na correção do erro, porém não exibe a solução após diversas tentativas; há sinalização de erro ou acerto da atividade e, no nível 2, conduz o estudante, fornecendo-lhe explicações para a correção; não há fornecimento da solução após longa persistência do erro e não se verifica a presença de som e efeitos sonoros pertinentes ao contexto. De modo geral, considera-se que esta dimensão foi contemplada satisfatoriamente podendo contribuir positivamente na interação entre SE-estudante.

Na dimensão Pedagógica o Dentro das Leis também obteve conceito Bom, pois em apenas quatro critérios obteve nível 0 , correspondente à explicitação dos fundamentos pedagógicos que o embasam; abordagem interdisciplinar; registro de desempenho dos estudantes nas atividades e favorecimento ao trabalho em equipe. O software ainda obteve nível 2 referente ao favorecimento da interpretação do estudante sobre seus erros e acertos, ajudando-o a ver suas respostas sob diferentes ângulos. Todavia obteve níveis 3 e 4 nos demais critérios referentes à documentação; objetivos e conteúdo pedagógicos; presença de recursos motivacionais que despertem e mantenham a atenção do estudante ao longo da interação e provimento de feedback isento de carga negativa. Nesta dimensão, portanto, o SE fornece bons subsídios para que a prática pedagógica possa ser viabilizada satisfatoriamente.

\subsection{Avaliação dos softwares educativos pelos participantes}

Os participantes do curso estavam motivados para participar da avaliação de softwares educativos de suas respectivas áreas e cada um deles se envolveu em todas as etapas do processo.

Ao analisar o material produzido pelos participantes, foi possível constatar que as avaliações se aproximaram das realizadas pela equipe executora do curso, tendo as classificações dos SE conceitos Bom e Ótimo, apesar de alguns critérios, não contemplados no SE, terem sido classificados como "não se aplica" e outros em níveis abaixo ou acima do esperado. Assim, percebe-se que os docentes em formação conseguiram desenvolver e aplicar conhecimentos relativos à função docente, especificamente a avaliação softwares educativos de maneira criteriosa, observando as especificidades do ambiente digital, da prática pedagógica e do ensino da área de conhecimento da qual fazem parte.

Os resultados ainda revelam a compreensão, desenvolvida pelos participantes, da importância e da necessidade de avaliar antecipadamente o material didático-pedagógico que almejam trabalhar com seus estudantes, cultivando, assim, um senso crítico nos docentes em formação. Atribuíram-se tais resultados à adoção de abordagens inter e transdisciplinar propostas neste trabalho, as quais estão presentes ao se utilizar da informática para o processo de ensino e aprendizagem de conteúdos de Química, Física, Matemática e Língua Portuguesa. Ainda, à presença de abordagens sobre a prática pedagógica e as especificidades do ambiente digital considerando as teorias sobre esse assunto.

Outros aspectos também foram percebidos em relação às três categorias analisadas nos SE. As avaliações da dimensão técnica realizadas pelos professores em formação sugerem que nem todos conhecem os elementos da interface de um programa. Provavelmente não 
compreenderam termos como link e feedback, apesar de interagirem com estes elementos constantemente. Neste sentido, cursos como o realizado neste projeto podem contribuir com o letramento digital de futuros professores, possibilitando que eles se apropriem das tecnologias digitais e exerçam práticas leitoras na tela. Por outro lado, uma parcela dos participantes compreendeu de modo satisfatório os critérios da dimensão técnica, ao ponto de propor melhorias nesta dimensão nos softwares avaliados.

No que se refere à dimensão pedagógica, foi possível verificar comentários mais consistentes na avaliação dos softwares e condizentes com a proposta no projeto. Em comentários produzidos pelos participantes, observou-se que diversos aspectos pedagógicos foram percebidos como importantes num SE, a exemplo dos objetivos de aprendizagem e adequação de conteúdos ao público-alvo do programa, bem como a importância da sua apresentação em diferentes níveis de complexidade. Além disso, a necessidade do professor intervir durante o uso de SE nas atividades dos alunos foi evidenciada por participantes em suas análises. Outra questão diz respeito à proposição de melhorias nos SE avaliados que favoreçam a aprendizagem dos estudantes.

O quadro de critérios de avaliação de SE proposto por Silva (2012) contempla, na dimensão específica, aspectos referentes à Leitura e Compreensão Textual. Desse modo, foi proposto aos graduandos em Física, Química, Matemática e Pedagogia que elaborassem critérios específicos na área de sua formação. Tal atividade evidenciou a necessidade de se ter critérios específicos para avaliação de softwares destinados às diversas disciplinas e envolveu os participantes no estudo de teorias atualizadas que fundamentam o ensino de conteúdos de suas respectivas áreas.

Com a análise dos critérios produzidos, percebeu-se a preocupação dos graduandos com a contextualização dos conteúdos específicos ao cotidiano dos hipotéticos alunos, público alvo do SE. Neste sentido, a relação teoria e prática foi o aspecto que apareceu em maior proporção nos critérios construídos pelos participantes. De modo complementar, comentários que fundamentam a avaliação quantitativa dos SE foram realizados, evidenciando a compreensão, por parte dos graduandos, da necessidade de uma intervenção reflexiva a partir de uma leitura da realidade dos seus futuros alunos. De modo geral, sobre a parte específica, percebeu-se, além da consideração da importância da contextualização dos conteúdos ao cotidiano do usuário, a elaboração de critérios relacionados a exemplos que auxiliam na compreensão dos conteúdos; a preocupação de elucidar os conteúdos prévios necessários à realização das atividades; a percepção da necessidade de inserção de exercícios práticos.

\section{Considerações finais}

$\mathrm{Na}$ formação de docentes é preciso considerar a necessidade de avaliar os materiais didáticopedagógicos, neste trabalho os softwares educativos, bem como elaborá-los, pois possivelmente os futuros docentes irão se deparar com tais materiais na sua prática em sala de aula e, se não houver uma preparação para um olhar crítico, provavelmente não conseguirão distinguir os materiais eficientes dos não eficientes. Por outro lado, quando o profissional da educação não tem essa oportunidade, na sua formação inicial, deve ir em busca de outras maneiras para conseguir ter habilidade para essa distinção, é quando se fala em formação continuada proporcionada por instituições preparadas para esse fim.

Nesta perspectiva, de dar suporte aos futuros docentes, foi realizado um curso envolvendo a participação de graduandos em Química, Física, Matemática e Pedagogia, objetivando proporcionar aos participantes embasamento teórico sobre o que subjaz aos 
processos de ensino e de aprendizagem, utilização de materiais didático-pedagógicos, softwares educativos e avaliação e produção de softwares educativos, bem como realizar a avaliação e produção desses materiais. Neste trabalho, foram apresentados os resultados obtidos com as atividades de avaliação de SE as quais possibilitaram a análise de materiais digitais considerando aspectos técnicos, pedagógicos e específicos das áreas supracitadas.

Com este curso foi possível propiciar aos graduandos de licenciaturas, mesmo não esgotando todas as possibilidades de avaliação de $\mathrm{SE}$ e todos os critérios que se possam considerar, entendimento no que subjaz a um material didático-pedagógico do meio digital, alertando para os diversos aspectos relacionados ao material e não se atendo à interface que é, na maioria, das vezes o ponto crucial de preocupação de avaliadores. Nesta perspectiva, foi possível verificar o entendimento dos graduandos, quando na avaliação, da natureza do SE e dos diversos aspectos que o compõem. Mesmo com algumas dificuldades de identificação dos níveis de ocorrência dos critérios, na maioria das vezes, os participantes conseguiam identificar tais critérios no SE em análise.

O senso crítico e reflexivo sobre os materiais também foi percebido, pois os estudantes realizavam suas análises com muito cuidado e solicitavam orientações aos executores naquilo que tinham dúvida. Espera-se, com esse curso, ter contribuído com a formação de professores e o exercício de sua profissão no que concerne ao uso de SE na educação e que a divulgação deste trabalho possa viabilizar outros eventos dessa natureza.

\section{Referências}

Bakhtin, M. M. (2003). Estética de criação verbal. Trad. Paulo Bezerra. São Paulo: Martins Fontes.

Bastos, Maria I. (2010). O desenvolvimento de competências em "TIC para a educação" na formação de docentes na América Latina. Brasília: UNESCO.

Gomes, A. S. (2008). "Referencial teórico construtivista para avaliação de software educativo". Revista Brasileira de Informática na Educação, 16(2).

Oliveira, E. R., Prates, R. O., \& Werneck, G. A. (2010). “Considerações sobre Aplicação do Método de Avaliação de Comunicabilidade ao domínio educacional”. In Proceedings of the IX Symposium on Human Factors in Computing Systems.

Peres, F. (2007). Diálogo e autoria: do desenvolvimento ao uso de sistemas de informação. Tese de doutorado. Recife: Universidade Federal de Pernambuco.

Preece, J., Rogers, Y., \& Sharp, H. (2005). Design de interação: além da interação homemcomputador. Porto Alegre: Bookman.

Silva, A. C. B. da. (2012). Softwares Educativos: Critérios de Avaliação a partir dos Discursos da Interface, da Esfera Comunicativa e do Objeto de Ensino. Tese de doutorado. Recife: Programa de Pós-graduação em Educação. Universidade Federal de Pernambuco.

Soares, M. M. \& Falcão, C. S. (2013). "Design, Ergonomia e Novas Tecnologias na Educação". In Anais do $6^{\circ}$ Congresso Nacional de Ambientes Hipermídia para Aprendizagem.

Valdivia, I. J. (2008). Las políticas de tecnología para escuelas en América Latina y el mundo: visiones y lecciones, Santiago de Chile, Naciones Unidas. 